\title{
Correction to: Performance Analysis of Cooperative Spectrum Sensing Network Using Optimization Technique in Different Fading Channels
}

\author{
M. Ranjeeth ${ }^{1} \cdot$ S. Anuradha ${ }^{1} \cdot$ Srinivas Nallagonda $^{2}$
}

\section{Correction to: Wireless Pers Commun (2017) 97:2887-2909 https://doi.org/10.1007/s11277-017-4640-2}

The last author's affiliation was incorrect in the original publication. The correct affiliation is ECE Department, Marri Laxman Reddy Institute of Technology and Management, Dundigal, India.

The original article can be found online at https://doi.org/10.1007/s11277-017-4640-2.

\section{Ranjeeth}

ranjithmamidi2001@gmail.com

S. Anuradha

anuradha@nitw.ac.in

Srinivas Nallagonda

srinivas.nallagonda@gmail.com

1 ECE Department, National Institute of Technology, Warangal, India

2 ECE Department, Marri Laxman Reddy Institute of Technology and Management, Dundigal, India 